Article

\title{
Barriers and Facilitators of Physical Activity in Children of a South Asian Ethnicity
}

\author{
Lee Smith ${ }^{1, *}$, Guillermo Felipe López Sánchez ${ }^{2}$ (D), Arturo Díaz Suárez ${ }^{2}$, Brendon Stubbs ${ }^{3}$, \\ Mathew Dowling ${ }^{4}{ }^{(\mathbb{D}}$, Adrian Scruton ${ }^{4}$, Justin Roberts ${ }^{4}{ }^{(\mathbb{D}}$, James Johnstone ${ }^{4}$ and Shahina Pardhan ${ }^{5}$ \\ 1 Cambridge Centre for Sport and Exercise Science, Anglia Ruskin University, Cambridge CB1 1PT, UK \\ 2 Faculty of Sports Sciences, University of Murcia, 30100 Murcia, Spain; gfls@um.es (G.F.L.S.); \\ ardiaz@um.es (A.D.S.) \\ 3 Faculty of Health, Social Care and Education, Anglia Ruskin University, Cambridge CB1 1PT, UK; \\ brendon.stubbs@kcl.ac.uk \\ 4 Cambridge Centre for Sport and Exercise Science, Anglia Ruskin University, Cambridge CB1 1PT, UK; \\ mathew.dowling@anglia.ac.uk (M.D.); adrian.scruton@anglia.ac.uk (A.S.); justin.roberts@anglia.ac.uk (J.R.); \\ james.johnstone@anglia.ac.uk (J.J.) \\ 5 Vision and Eye Research Unit, Anglia Ruskin University, Cambridge CB1 1PT, UK; \\ Shahina.Pardhan@anglia.ac.uk \\ * Correspondence: Lee.Smith@anglia.ac.uk; Tel.: +44-0795-1893-837
}

Received: 10 February 2018; Accepted: 8 March 2018; Published: 9 March 2018

\begin{abstract}
Children of South Asian ethnicity residing in England have low levels of physical activity. Limited literature exists on correlates, barriers, and facilitators to activity in South Asian children. The aim of this study was to fill this gap in the literature. Interviews were conducted with 10 parents of South Asian ethnicity residing in the UK. Interviews covered a description of the family setup, participants' opinions of physical activity including barriers and facilitators and their children's participation, as well as approaches to general parenting, and how children spend their free time. Data were analysed using thematic analysis. Key themes identified included (i) restraints on parents' and children's time to be physically active; (ii) the role of the family in children's physical activity participation; (iii) situational barriers to physical activity; (iv) physical activity not a priority; (v) opportunities to be active; and (vi) perception of activity level and health. A number of key barriers to South Asian children's participation in physical activity were identified, including (i) restraints on parents and children's time; (ii) parents providing limited support for physical activity; and (iii) physical activity having a low priority. A number of facilitators were also identified (i) play; (ii) school-time; and (iii) extra-curricular clubs. In this sample of South Asian parents residing in the UK several socio-cultural barriers and facilitators of their children's physical activity have been identified. The study provides preliminary data for a larger study to ascertain if such barriers and facilitators are representative of the wider South Asian community, so that recommendations for intervention and policies can be made.
\end{abstract}

Keywords: physical activity; health; schoolchildren

\section{Introduction}

The Health Survey for England [1] found that all minority ethnic groups have a higher risk of diabetes when compared to other ethnicities. Moreover, literature shows that British South Asian adults have about six-times increased risk of Type II diabetes compared to Caucasians [2,3]. Research has also found that British South Asians are at increased risk of Type II diabetes in childhood and adolescence [4-6], suggesting that this difference in risk of diabetes presents itself in the early years of life. 
Sustained and regular participation in physical activity aids in the prevention and control of Type II diabetes $[7,8]$. Guidelines recommend that children and young people (5-18 years) should achieve at least $60 \mathrm{~min}$ of moderate-to-vigorous activity every day. However, despite such guidelines, population levels of physical activity in children and young people are low. Excluding school based activities, 22\% of children aged between 5 and 15 years met the physical activity guidelines of being at least moderately active for at least $60 \mathrm{~min}$ every day (23\% of boys, $20 \%$ of girls) [9]. Several studies have found that physical activity levels differ by ethnicity $[10,11]$. In a recent longitudinal study of 281 children residing in Camden, London. it was found that children of a South Asian ethnicity had lower levels of moderate-to-vigorous physical activity at baseline and one-year follow-up when compared to those of a Caucasian/mixed ethnicity. Children of a South Asian ethnicity were also found to have a significantly greater increase in time spent sedentary at follow-up [12]. This is of concern as South Asians are at increased risk of Type II diabetes early in life [4-6], and high levels of physical activity and low levels of sedentary behaviour are associated with incident diabetes, through promoting visceral adiposity and impaired glucose control $[13,14]$. The reasons for these observed differences in physical activity between children of different ethnic groups are poorly understood. Research identifying correlates that are associated with activity levels in South Asian children is needed to inform effective intervention. Identifying correlates of physical activity can inform intervention development by highlighting potentially modifiable correlates that may bring about physical activity (e.g., physical environment), or identify characteristics of target groups most in need of intervention (e.g., lack of awareness, socio-economic-status).

A large body of literature exists on correlates of children's total physical activity [15], time specific physical activity (school break time and after school periods) [16], active travel [17], and sport [18]. However, correlates, barriers, and facilitators to activity in South Asian children has been studied less. Parents are the gate keepers to children's independence and often make key decisions for their children relating to physical activity, so it is important to interview parents to identify barriers and facilitators to children's physical activity. Qualitative research is required to investigate barriers and facilitators to physical activity participation in South Asian children to provide context to current findings of low levels of activity in this population and to capture further expressive information.

The present study aimed to explore South Asian parents' attitudes towards physical activity and potential barriers and facilitators of engagement. For the present study, a qualitative methodology was chosen because we were not seeking to test a hypothesis, but rather sought to obtain a rich source of information to better understand physical activity behaviour, or lack thereof, in South Asian children [19].

\section{Materials and Methods}

\subsection{Participants and Procedures}

Participants were recruited via several methods through flyers and posters placed around Anglia Ruskin University Campus, through emailing several South Asian groups in Cambridgeshire, and via social media. Inclusion criteria for the study included being of a South Asian ethnicity and a parent of a child(ren) any age under that of 18 years. Those interested in the study and eligible were given an information sheet and told that the aim of the study was to help learn more about what parents of South Asian children think about lifestyle. They were given the opportunity to ask questions and we then obtained signed informed consent. Ethical approval was granted by the Anglia Ruskin University Sport and Exercise Science Departmental Ethics Committee.

\subsection{Data Collection}

Consenting participants were interviewed by trained research staff. No participants were excluded based on where they lived. For logistical reasons, either face-to-face or over the telephone interviews were offered, however, all participants opted for telephone interviews. One experienced interviewer 
carried out the interviews in English during the months of June and July 2017 and all interviews were recorded and transcribed verbatim. Interviews followed a topic guide, developed by three researchers and informed by existing literature, to explore South Asian parents' views on physical activity and their children's physical activity behaviour. The guide covered a description of the family setup, participants' opinions of physical activity including barriers and facilitators and their children's participation, as well as approaches to parenting, and how children spend their free time. Participants were asked to talk about each topic in the guide, with the interviewer trained to have minimal verbal input and prompt only when appropriate. The topic guide was piloted with two participants whose data were included because no substantial changes were required. Emerging themes were discussed during the data collection period, and data collection continued until it was felt saturation had been reached.

\subsection{Analysis}

Data were analysed using thematic analysis, a qualitative method for identifying, analyzing, and reporting themes [20]. Thematic analysis was chosen to provide a rich description of the data and to identify themes using a realist approach [20]. The first three transcripts were reviewed independently by two researchers who each generated an initial list of codes by hand. Codes were generated using emergent thematic coding, a qualitative data analysis approach in which transcripts are read several times to identify themes that emerge from the data. These lists were then amended and refined through discussion between the researchers until a single list was agreed. Once the coding had been agreed the two researchers reviewed the coded transcripts to search for common themes. These themes were reviewed and refined, named, and each given a written description.

\section{Results}

All participants classed themselves and their children as being of South Asian ethnicity, and of the 10 participants, 4 were Bangladeshi, 1 Pakistani, and 5 Indian. All participants classed themselves as religious, six Hindu and four Muslim, with an average number of two children per family with an average child age of 8.6 years. Five parents interviewed were female and five were male (Table 1). All interviewed parents had achieved a high level of education (e.g., degree).

Table 1. Description of participants.

\begin{tabular}{ccccccc}
\hline Participant & $\begin{array}{c}\text { Sex of Parent } \\
\text { Interviewed }\end{array}$ & Ethnicity & Religion & $\begin{array}{c}\text { Number of } \\
\text { Children }\end{array}$ & $\begin{array}{c}\text { Age of } \\
\text { Child/Children }\end{array}$ & $\begin{array}{c}\text { Sex of } \\
\text { Child/Children }\end{array}$ \\
\hline A & Female & Bangladeshi & Hindu & 1 & 11 & Female \\
B & Female & Pakistani & Muslim & 4 & 5 (twins), 12, 13 & 2 Male, 2 Female \\
C & Male & Indian & Hindu & 1 & 1 & Male \\
D & Female & Indian & Hindu & 2 & 6 months, 5 & Female, Male \\
E & Male & Bangladeshi & Muslim & 2 & 9,14 & Female \\
F & Male & Bangladeshi & Muslim & 1 & 7 & Female \\
G & Male & Bangladeshi & Muslim & 2 & 17 (twins) & 2 Male \\
H & Female & Indian & Hindu & 1 & 11 months & Female \\
I & Female & Indian & Hindu & 1 & 8 & Female \\
J & Male & Indian & Hindu & 1 & 8 & Female \\
\hline
\end{tabular}

\subsection{Themes}

A total of six themes were identified: (i) Restraints on parents' and children's time to be physically active; (ii) the role of the family in children's physical activity participation; (iii) situational barriers to physical activity; (iv) physical activity not a priority; (v) opportunities to be active; and (vi) perception of activity level and health (Table 2). 
Table 2. Summary of findings.

\begin{tabular}{|c|c|c|c|}
\hline Themes & Sub Themes & $\begin{array}{l}\text { Coding } \\
\text { Density }\end{array}$ & Anchor Examples \\
\hline \multirow[b]{2}{*}{$\begin{array}{l}\text { Restraints on parents' and } \\
\text { children's time to be } \\
\text { physically active }\end{array}$} & $\begin{array}{l}\text { (i) parental time restraints to } \\
\text { be physically active }\end{array}$ & 7 & $\begin{array}{l}\text { "I like swimming but I have no time to } \\
\text { go."-participant G }\end{array}$ \\
\hline & $\begin{array}{l}\text { (ii) parents' time restraints } \\
\text { burdening their children's } \\
\text { activity levels }\end{array}$ & 7 & $\begin{array}{l}\text { "So many times she [child] will say daddy can we go } \\
\text { to the park daddy can we go for a cycle and daddy } \\
\text { will say no I'm really busy." - participant I }\end{array}$ \\
\hline \multirow[b]{2}{*}{$\begin{array}{l}\text { The role of the family in } \\
\text { children's physical activity } \\
\text { participation }\end{array}$} & $\begin{array}{l}\text { (i) the role of the parent in } \\
\text { children's physical activity } \\
\text { behaviour }\end{array}$ & 14 & $\begin{array}{l}\text { "I think not having the role model from her dad } \\
\text { hasn't made it a priority."-participant I }\end{array}$ \\
\hline & $\begin{array}{l}\text { (ii) the level of independence } \\
\text { granted to the child by the } \\
\text { parent }\end{array}$ & 10 & $\begin{array}{l}\text { "We always like [to] know where my daughter is, so } \\
\text { she is just one single child so it makes us a bit more } \\
\text { protective of her."-participant A }\end{array}$ \\
\hline \multirow{2}{*}{$\begin{array}{l}\text { Situational barriers to } \\
\text { physical activity }\end{array}$} & Climate & 4 & $\begin{array}{l}\text { "When its winter and when it's like not good } \\
\text { weather we don't actually go out } \\
\text { anywhere."-participant A }\end{array}$ \\
\hline & Access & 4 & $\begin{array}{l}\text { "If there was something very close by she could go } \\
\text { to [to be active] we could send her in the weekends } \\
\text { or something."- participant A }\end{array}$ \\
\hline $\begin{array}{l}\text { Physical activity not a } \\
\text { priority }\end{array}$ & - & 7 & $\begin{array}{l}\text { "There was not much physical activity, nobody } \\
\text { motivated you and [it] wasn't understood that you } \\
\text { could learn a particular game or sport and there was } \\
\text { no place to do it either."-participant H. }\end{array}$ \\
\hline \multirow[t]{2}{*}{ Opportunities to be active } & School & 17 & $\begin{array}{l}\text { "During playtime at school she always } \\
\text { plays." - participant F }\end{array}$ \\
\hline & Extra-curricular & 12 & $\begin{array}{l}\text { "My daughter does swimming after } \\
\text { school."-participant B }\end{array}$ \\
\hline \multirow{3}{*}{$\begin{array}{l}\text { Perception of activity level } \\
\text { and health }\end{array}$} & $\begin{array}{l}\text { (i) perception of own activity } \\
\text { levels and health }\end{array}$ & 12 & "We [parents] are not very physical." — participant A \\
\hline & $\begin{array}{l}\text { (ii) perception of child's } \\
\text { activity levels and health }\end{array}$ & 17 & $\begin{array}{l}\text { "They [children] are ok, would want them to be } \\
\text { more active but they are not bad."-participant E }\end{array}$ \\
\hline & $\begin{array}{l}\text { (iii) understanding of } \\
\text { recommendations for } \\
\text { physical activity }\end{array}$ & 4 & "I think 30 min every day." — participant I \\
\hline
\end{tabular}

\subsection{Restraints on Parents' and Children's Time to Be Physically Active}

Several parents commented on the restraints on their and their children's time to be physically active. Within this theme three sub themes were identified (i) parental time restraints to be physically active; (ii) parents' time restraints burdening their children's activity levels; and (iii) children's time restraints to be physically active. Many parents expressed that they wanted to participate in physical activity, however, because of a lack of discretionary time they were not able to. For example, "I like swimming but I have no time to go" [participant G], and "I don't do things [physical activity] I might have done previously just because of time" [participant $C$ ]. Parents believed that time restraints on their activity levels also influenced that of their children. For example, "we are all very exhausted by the end of the day and because we work full time both of us are restricted in the number of hours we can give her [child] to do physical activities" [participant A], and "so many times she [child] will say daddy can we go to the park daddy can we go for a cycle and daddy will say no I'm really busy" 
[participant I]. Parents also suggested that children do not get time to be active, sometimes owing to external commitments such as homework. For example, "in the short time she gets, she plays by herself" [participant F], and "because of their ages now they got tons of homework and you know from Monday onwards their diaries are packed with homework ... So, ... their schedule at school and things like that gets in the way [of physical activity] a lot" [participant B].

\subsection{The Role of the Family in Children's Physical Activity Participation}

Parents often commented on the role of the family in relation to physical activity for which a total of three sub themes were identified (i) the role of the parent in children's physical activity behaviour; (ii) the level of independence granted to the child by the parent; and (iii) the role of siblings in children's activity levels.

Parents suggested that there is not direct modelling of ideal behaviour from parents "I think not having the role model from her dad hasn't made it [physical activity] a priority" [participant I]. However, parents expressed that they wanted to be role models for children's physical activity behaviour "I do have this idea that I want to kinda do stuff together, activities whether that's activities indoors, games or thing or stuff outdoors, something a bit sport or physical" [participant C]. Some parents encouraged their children's physical activity through providing support for physical activity, for example "we have tried to enroll her in activities that involve physical activity" [participant A].

Parents reported that they grant their children low levels of independence. For example, "they are not allowed out at home time ... going out with friend and socialising and that aspect no" [participant B] and "we always like [to] know where my daughter is, so she is just one single child so it makes us a bit more protective of her" [participant A]. Whereas other participants articulated granting their child(ren) higher levels of independence, but at the same time providing children with the support to be independent. For example, "we liked to know where they are but at the same time because they are growing up, depending on what age they are we try to give them the freedom" [participant E] and "Well I think erm firm but fair so erm obviously oldest child is five so he's a bit more independent but we provide guidance" [participant D].

The role of siblings was outlined by one parent, stating that not having someone to be active with reduces activity levels "she wants to do something and wants someone to do it with I think, not having another sibling, things would be different and children can play together" [participant I].

\subsection{Situational Barriers to Physical Activity}

Participants outlined two situational barriers preventing physical activity in their children, sub themed climate and access. Participants expressed the negative impact weather has on the ability to do physical activity, for example: "When its winter and when it's like not good weather we don't actually go out anywhere" [participant A] and "obviously if the weather is poor they [children] can't go out to the park with us or they can't go out to the back garden" [participant B]. Access was also outlined as a barrier. For example, "if there was something very close by she could go to [to be active] we could send her in the weekends or something" [participant A].

\subsection{Physical Activity Is Not a Priority}

Participants described the impact their culture has on their level of physical activity, suggesting that physical activity has a relatively low level of importance (compared to more academic pursuits) in the South Asian community: "academic qualifications or getting medical qualifications, something that is very tangible that will get you a job and lively hood is seen as a better use of time than playing or using your time to do a sport ... this whole mind set, sport is a waste of time you would be better off learning a skill or making money" [participant I]. Owing to this low level of importance it is suggested that sport and exercise is not encouraged from a young age: "there was not much physical activity nobody motivated you and [it] wasn't understood that you could learn a particular game or sport and there was no place to do it either" [participant H]. 


\subsection{Opportunities to Be Physically Active}

Play, discretionary time, school time, and extra-curricular clubs were identified as opportunities for which South Asian children may partake in physical activity.

Participants described that their child is getting physical activity though playing per se and particularly playing during limited discretionary time. For example, "in the short time she gets, she plays by herself" [participant F], "if they have the time they go play games in the evening" [participant G], and "he likes to do play fighting" [participant D]. During discretionary time, the garden is also described as somewhere where children can be active; "in the limited time, we have we go into the garden and play" [participant E] and "we do garden [to be active] sometimes" [participant A].

Parents described the school as a place where their children are active: For example, "during playtime at school she always plays" [participant F], "he just plays football at lunch time" [participant B], and "the last conversation I had it seemed they were active during their breaks" [participant E]. Moreover, extracurricular clubs were perceived to provide an opportunity for physical activity. For example, "my daughter does swimming after school" [participant B], "[son] goes to basketball every day" [participant G], and "on Thursday, he attends an after-school club multi sports for an additional hour as well ... so its playing cricket, football" [participant D].

\subsection{Perception of Activity Levels and Health}

Participants discussed perceptions on theirs and their family's activity levels and health. Three sub-themes were identified (i) perception of own activity levels and health; (ii) perception of child's activity levels and health; and (iii) understanding of recommendations for physical activity. Parents believed that they were inactive and needed to be healthier. For example, "we [parents] are not very physical" [participant A], and "I wouldn't say I am very active" [participant E]. Further to this, participants discussed their perception of their children's activity levels and health, outlining moderate levels of activity but also a need to improve; "they [children] are ok, would want them to be more active but they are not bad" [participant E], and "I think she needs to be healthier and she needs to eat healthy foods and do some more physical activities because she's growing up" [participant F]. However, other participants had the opinion that their children are active, for example: "yeah definitely, they [the children] are very active" [participant D], and "the younger two are a little more active erm, so they are always jumping about and running around, you know they got more energy than the older two a bit" [participant B].

In order to understand what participants are comparing activity levels to, parents were asked the question "what are the recommended levels of physical activity for children". Responses varied, suggesting confusion in this community on how active children should be. For example, "I think $30 \mathrm{~min}$ every day" [participant I], "I'm expecting her to be physically active when she's in the playground three times a day" [participant A], and " 20 min of activity that's erm of a sufficiently aerobic nature ... I would say between the moderate and vigorous range" [participant J].

\section{Discussion}

The aim of this study was to explore South Asian parents' attitudes towards physical activity and potential barriers and facilitators to their child(ren)'s physical activity engagement. In this qualitative study of South Asian parents residing in the UK, a number of key barriers to South Asian children's participation in physical activity were identified, including (i) restraints on parents and children's time; (ii) parents providing limited support for physical activity, specifically not acting as a role model; and (iii) physical activity has a low priority. The present study has also identified a number of facilitators of physical activity that included: (i) play; (ii) school-time; and (iii) extra-curricular clubs. On the whole, parents acknowledge that their children need to be more physically active, but demonstrated confusion about how active they should be. 


\subsection{What Is Already Known on This Topic and What This Study Adds?}

Many parents commented on time restrictions limiting their physical activity levels and that of their children. This is an interesting finding and one that may be specific to children of a South Asian ethnicity. Previous reviews that have investigated barriers and facilitators to children's physical activity have not identified time restraints as a barrier to engagement [15]. However, it has been previously identified as a barrier in adults [21]. This may be a barrier specific to South Asian children (and not of those from other ethnicities) owing to a low level of importance placed on physical activity within this community when compared to more academic related activities such as homework. Indeed, in the present paper, parents often commented that children's physical activity had a low level of importance in comparison to school work. This is supported by broader research. Smith et al. [12] found in a sample of 281 children that those of a South Asian ethnicity generally had a higher prevalence of sedentary activities such as TV viewing, computer use and homework. Gibson and Bachu [22] state that Sikhs and other Indian students do better on examinations taken at age 16 than students of English, Scottish, Welsh, and Irish origin. Taken together, these findings suggest that South Asian children's discretionary time, and thus free to be active, may be being replaced with traditional academic pursuits (e.g., homework).

This low level of importance placed on South Asian children's physical activity by parents may be resulting in relatively low levels of support for children's physical activity, particularly that of modelling. Indeed, in the present study parents commented that they were not role models of physical activity for their children. This is problematic as research suggests that parental support for physical activity is a key facilitator of the behaviour. For example, Moore et al. [23] found in a sample of 100 children and their parents that when both parents were active, their children were 5.8 times more likely to be active compared to children with two inactive parents. In another study of 102 preschool children those who perceived greater parental support for physical activity were 6.3 times more likely to be categorised as "highly active" than "inactive" [24].

In the present study, parents reported granting their children low levels of independence. This is likely to influence children's activity levels as, for example, children's independent outdoor play is likely to be more active than that of supervised outdoor play (play with a parent/guardian) [25]. Moreover, children who are granted independence to walk or cycling to school alone have higher levels of physical activity than those who are not [26]. Parents perceived their children to be active during school break times. However, this may not be correct. A recent study in an ethnically diverse sample of 231 inner-city London children found that on average children spent approximately $14 \mathrm{~min}$ a day in moderate-to-vigorous physical activity [12].

Findings from the present study suggest that a potential facilitator and avenue for intervention to improve physical activity among South Asian children is through play. Parents often commented that during the limited free time their children have they like to play. Active play (likely to be outdoor play) is a key domain of physical activity in children. Ensuring play in South Asian children is outdoors and of an active nature could be one avenue for physical activity promotion in the community. This could be achieved by providing safe play spaces in local communities [27] or opening school playgrounds during out of school hours. Another domain of children's physical activity that may be utilised to promote physical activity in children of a South Asian ethnicity is organised sport. In the present study parents commented that they are willing to take their children to extracurricular activities. Interestingly, parents acknowledge that their children need to be physically activity but they were unsure on how active their children should be. This is supported by previous literature in multiple ethnicities. For example, Sawyer and colleagues [28] found in a sample of 1113 families that just 21\% of primary caregivers in the UK knew the recommended amount of physical activity for UK children. Dissemination of physical activity guidelines specifically targeting South Asian parents could be an important step to increasing physical activity in this community. 


\subsection{Strengths and Limitations}

This is the first study to explore South Asian parental perceptions of barriers and facilitators to their children's physical activity. However, it should be acknowledged that similar work has been carried out with young people and in South Asian communities [21,29]. In the present study, current and previous physical activity levels were not considered. Those interested in our study may be those with a long-term interest in physical activity. Interview transcripts were not returned to participants for comments and/or corrections after the interviews, which would have given participants the opportunity to verify the content and quality of the transcripts.

\section{Conclusions}

In this sample of South Asian parents residing in the UK, several socio-cultural barriers and facilitators of their children's physical activity have been identified. The study provides preliminary data for a larger study to ascertain if such barriers and facilitators are representative of the wider South Asian community, so that recommendations for intervention and policies can be made.

Acknowledgments: We would like to thank all the subjects that participated in this study, and all the people who helped in the data collection.

Author Contributions: L.S., G.F.L.S., A.D.S., B.S., M.D., A.S., J.R., J.J. and S.P. conceived and designed the study, analyzed the data, and wrote the paper.

Conflicts of Interest: The authors declare no conflict of interest.

\section{References}

1. Public Health England. Adult Obesity and Type 2 Diabetes. 2014. Available online: https://www.gov.uk/ government/publications/adult-obesity-and-type-2-diabetes (accessed on 10 February 2018).

2. McKeigue, P.M.; Shah, B.; Marmot, M.G. Relation of central obesity and insulin resistance with high diabetes prevalence and cardiovascular risk in South Asians. Lancet 1991, 337, 382-386. [CrossRef]

3. Bhopal, R.; Unwin, N.; White, M.; Yallop, J.; Walker, L.; Alberti, K.G.M.M.; Harland, J.; Patel, S.; Ahmad, N.; Turner, C.; et al. Heterogeneity of coronary heart disease risk factors in Indian, Pakistani, Bangladeshi, and European origin populations: Cross sectional study. Br. Med. J. 1999, 319, 215-220. [CrossRef]

4. Whincup, P.H.; Owen, C.G.; Orfei, L.; McKay, C.; Cook, D.G. Ethnic differences in risk factors for chronic disease have their origins in early life: Evidence for the CHASE study. Early Hum. Dev. 2007, 83, S63. [CrossRef]

5. Whincup, P.H.; Gilg, J.A.; Papacosta, O.; Seymour, C.; Miller, G.J.; Alberti, K.G.M.M.; Cook, D.G. Early evidence of ethnic differences in cardiovascular risk: Cross sectional comparison of British South Asian and white children. Br. Med. J. 2002, 324, 635. [CrossRef]

6. Whincup, P.H.; Gilg, J.A.; Oweb, C.G.; Odoki, K.; Alberti, K.G.; Cook, D.G. British South Asians aged 13-16 years have higher fasting glucose and insulin levels than Europeans. Diabet. Med. 2005, 22, 1275-1277. [CrossRef] [PubMed]

7. Helmrich, S.P.; Ragland, D.R.; Leung, R.W.; Paffenbarger, R.S. Physical activity and reduced occurrence of non-insulin dependent diabetes mellitus. N. Engl. J. Med. 1991, 325, 147-152. [CrossRef] [PubMed]

8. Hu, F.B.; Sigal, R.J.; Rich-Edwards, J.W.; Colditz, G.A.; Solomon, C.G.; Willett, W.C.; Speizer, F.E.; Manson, J.E. Walking compared with vigorous physical activity and risk of type 2 diabetes in women: A prospective study. JAMA 1999, 282, 1433-1439. [CrossRef] [PubMed]

9. Scholes, S. Health Survey for England 2015: Physical Activity in Children. 2016. Available online: http:/ / www. content.digital.nhs.uk/catalogue/PUB22610/HSE2015-Sum-bklt.pdf (accessed on 10 February 2018).

10. Owen, C.G.; Nightingale, C.M.; Rudnicka, A.R.; Cook, D.G.; Ekelund, U.; Whincup, P.H. Ethnic and gender differences in physical activity levels among 9-10-year-old children of white European, South Asian and African-Caribbean origin: The Child Heart Study in England (CHASE Study). Int. J. Epidemiol. 2009, 38, 1082-1093. [CrossRef] [PubMed] 
11. Eyre, E.L.; Duncan, M.J.; Smith, E.C.; Matyka, K.A. Objectively measured patterns of physical activity in primary school children in Coventry: The influence of ethnicity. Diabet. Med. 2013, 30, 939-945. [CrossRef] [PubMed]

12. Smith, L.; Aggio, D.; Hamer, M. Longitudinal patterns in objective physical activity and sedentary time in a multi-ethnic sample of children from the UK. Pediatr. Obes. 2017, 1, 1-7. [CrossRef] [PubMed]

13. Murabito, J.; Pedley, A.; Massaro, J.; Vasan, R.S.; Esliger, D.; Blease, S.J.; Hoffman, U.; Fox, C.S. Moderate-to-vigorous physical activity with accelerometery is associated with visceral adipose tissue in adults. J. Am. Heart Assoc. 2015, 4, e001379. [CrossRef] [PubMed]

14. Dowse, G.K.; Zimmet, P.Z.; Gareeboo, H.; Alberti, K.G.M.; Tuomilehto, J.; Finch, C.F.; Chitson, P.; Tulsidas, H. Abdominal obesity and physical inactivity as risk factors for NIDDM and impaired glucose tolerance in Indian, Cerole, and Chinese Mauritians. Diabetes Care 1999, 14, 271-282. [CrossRef]

15. Sallis, J.F.; Prochaska, J.J.; Taylor, W.C. A review of correlates of physical activity of children and adolescents. Med. Sci. Sports Exerc. 2000, 35, 963-975. [CrossRef]

16. Stanley, R.; Ridley, K.; Dollman, J. Correlates of children's time-specific physical activity: A review of the literature. Int. J. Behav. Nutr. Phys. Act. 2012, 9, 1-13. [CrossRef] [PubMed]

17. Panter, J.; Jones, A.; van Sluijs, E. Environmental determinants of active travel in youth: A review and framework for future research. Int. J. Behav. Nutr. Phys. Act. 2008, 5, 1-14. [CrossRef] [PubMed]

18. Allen, M.S.; Vella, S.A. Are the correlates of sport participation similar to screen time? Prev. Med. Rep. 2015, 2, 114-117. [CrossRef] [PubMed]

19. Holliday, D. Analysing qualitative data. In Continuum Companion to Research Methods in Applied Linguistics; Paltridge, B., Phkiti, A., Eds.; Continuum: Melbourne, Australia, 2010.

20. Braun, V.; Clarke, V. Using thematic analysis in psychology. Qual. Res. Psychol. 2006, 3, 77-101. [CrossRef]

21. Allender, S.; Cowburn, G.; Foster, C. Understanding participation in sport and physical activity among children and adults: A review of qualitative studies. Health Educ. Res. 2006, 21, 826-835. [CrossRef] [PubMed]

22. Gibson, M.; Bhachu, P. Ethnicity and school performance: A comparative study of South Asian pupils in Britain and America. Ethn. Racial Stud. 1988, 3, 239-262. [CrossRef]

23. Moore, L.; Lombardi, D.; White, M.; Campbell, J.; Oliveria, S.; Ellison, C. Influence of parents' physical activity levels on activity levels of young children. J. Pediatr. 1991, 2, 215-219. [CrossRef]

24. Zecevic, C.A.; Tremblay, L.; Lovsin, T.; Michel, L. Parental influence on young children's physical activity. Int. J. Pediatr. 2010, 1, 1-9. [CrossRef] [PubMed]

25. Aggio, D.; Gardner, B.; Roberts, J.; Johnstone, J.; Stubbs, B.; Williams, G.; Lopez Sanchez, G.; Smith, L. Correlates of children's independent outdoor play: Cross-sectional analyses from the millennium cohort study. Prev. Med. Rep. 2017, 8, 10-14. [CrossRef] [PubMed]

26. Hamer, M.; Aggio, D.; Knock, G.; Kipps, C.; Shankar, A.; Smith, L. Effect of major school playground reconstruction on physical activity and sedentary behaviour: Camden Active Spaces. BMC Public Health 2017, 17, 552. [CrossRef] [PubMed]

27. Farley, T.; Meriwether, R.; Baker, E.; Watkins, L.; Johnson, C.; Webber, L. Safe play spaces to promote physical activity in inner-city children: Results from a pilot study of an environmental intervention. Am. J. Public Health 2007, 97, 1625-1631. [CrossRef] [PubMed]

28. Sawyer, A.; Smith, L.; Schrempft, S.; van Jaarsveld, C.H.; Wardle, J.; Fisher, A. Primary caregiver knowledge of paediatric physical activity recommendations in the United Kingdom and its association with caregiver behaviour: An observational study. BMC Public Health 2014, 14, 795. [CrossRef] [PubMed]

29. Johnson, M. Perceptions of barriers to healthy physical activity among Asian communities. Sport Educ. Soc. 2010, 5, 51-70. [CrossRef]

(C) 2018 by the authors. Licensee MDPI, Basel, Switzerland. This article is an open access article distributed under the terms and conditions of the Creative Commons Attribution (CC BY) license (http:/ / creativecommons.org/licenses/by/4.0/). 